\title{
Trigeminal trophic syndrome
}

\author{
Nigel Harper
}

Department of Geriatric Medicine, South Sefton Health District, Fazakerley Hospital, Liverpool L9 7AL, UK.

\begin{abstract}
Summary: Two cases of ulceration of the face following surgical sensory denervation are described. Both patients presented to a geriatric unit because of problems associated with mental impairment. There are relatively few reports of similar ulcers. A review of the literature suggests that mental impairment is an important aetiological factor.
\end{abstract}

\section{Introduction}

Ulceration of the face and erosion of the nose sometimes occurs following sensory denervation in the territory of the second division of the trigeminal nerve. The incidence is uncertain but relatively few cases have been described, mostly following surgical treatments for trigeminal neuralgia. It has come to be known as the trigeminal trophic syndrome although it is really a special form of dermatitis artifacta. Two women presenting with dementia who demonstrated this lesion are described.

\section{Case reports}

Case 1

An 82 year old woman presented in January, 1978 with poor mobility and falls due to an old ununited fracture of the right femoral neck with avascular necrosis of the femoral head. There was also a 6 month history of increasing confusion but this had not been causing any problems at home.

At the time of the original admission an ulcer was noted on the left nostril (Figure 1). This had been present for about a month prior to admission but, because she constantly picked and scratched it, it did not heal.

Ten years previously she had had a rhizotomy for trigeminal neuralgia. Although she could not remember the date or nature of this operation she vividly recalled the dramatic relief of pain. The pain had never recurred and she denied any abnormal sensation in the face. Complete facial hemi-anaesthesia was present on testing.

Local applications made no difference to the lesion. Healing was eventually obtained by a programme of

N. Harper, M.B., M.R.C.P.

Accepted: 19 July 1984 careful attention to the nails, wearing of cotton gloves, encouragement not to pick the area and diversionary activities (Figure 2). The difficulties of such treatment should not be underestimated. She eventually died in 1980.

\section{Case 2}

An 86 year old woman presented in June 1978 with poor mobility and falls.

When first seen there was an ulcer on the left nose and upper lip which she constantly picked and touched. She did this because she said she had an itchy feeling in the nose. On testing there was complete facial hemi-anaesthesia.

The following history was obtained from various sources. In 1961 she had developed trigeminal neuralgia. Dental extractions were carried out in 1962.

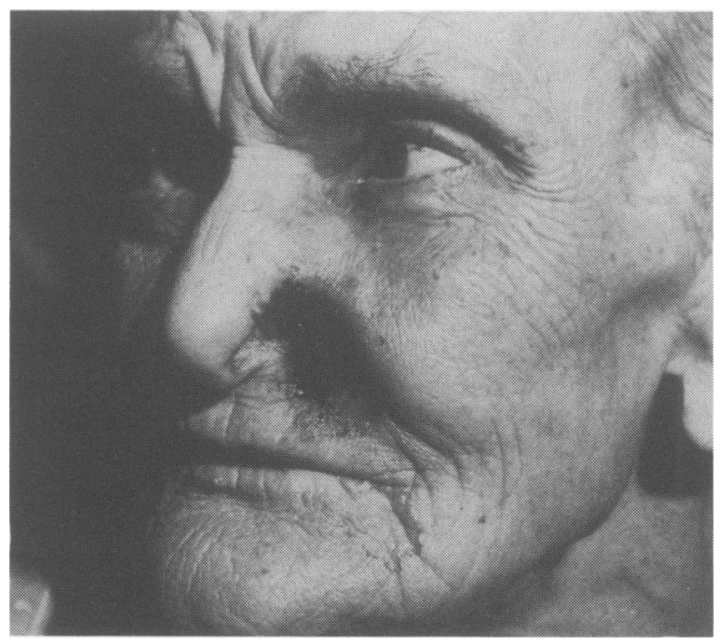

Figure 1 Case 1. Shows a typical crescentic defect.

(C) The Fellowship of Postgraduate Medicine, 1985 


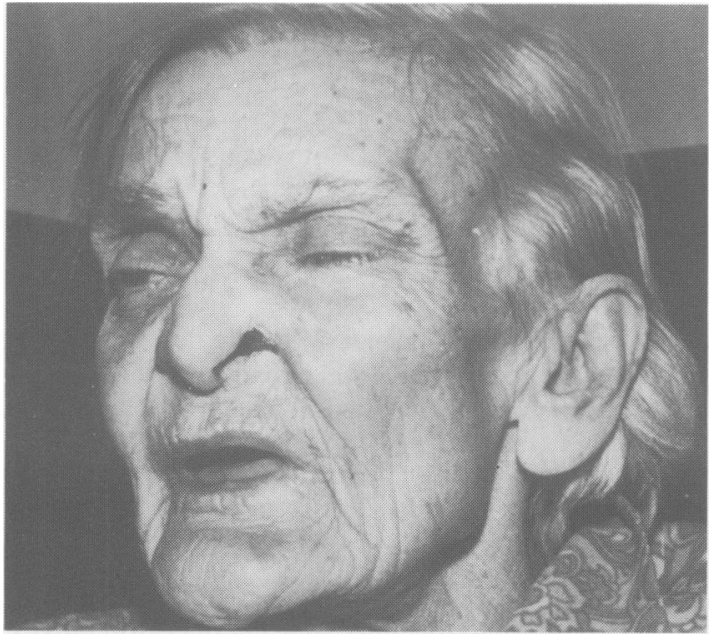

Figure 2 Case 1. Healing after a period of intensive treatment.

Alcohol injection was performed in April, 1965 and in September, 1965 she had had a rhizotomy. Complete facial hemi-anaesthesia was noted post-operatively. A facial ulcer was first noted in 1975 when it had been present 'several years'. She eventually died in February 1979.

\section{Discussion}

The incidence of nasal ulceration of the face following operation for trigeminal neuralgia is not clear. Spillane \& Wells (1959) describe it as the rarest complication of surgical denervation of the skin and face. More recently, Henderson (1967) quotes a remarkably high incidence of $16 \%$ of patients with total anaesthesia of the cheek (although this represents an incidence of $5 \%$ of all cases found on follow-up). Most series report only an occasional case (Peet \& Schneider 1952; McKenzie, 1933), a 'small proportion' (Harris, 1940) or none at all (Adson, 1926; Morello et al., 1971; Dade Lunsford, 1982).

The lesion is not widely known outside neurological and dermatological circles and there are few reports in the literature. I have been able to find descriptions of only 22 cases with a further 16 cases mentioned as part of surgical follow-up series without specific details. Similar ulcers can occur following other cases of facial anaesthesia, particularly trigeminal neuropathy (Spillane \& Wells, 1959) and brain stem lesions (Freeman, 1966). A further 9 cases are of this type making 47 reports in all.

In most cases a crescentic deficit is seen, corresponding to the area of the nose lacking in cartilage ('ulceration en arc', Jaeger 1950). In the more severe cases (Figure 3) scarring and tissue loss in the upper lip results in drawing up of the mucocutaneous junction, giving a characteristic 'sneer' (Howell, 1962).

Many early authors regarded these lesions as due to disorder of skin nutrition (i.e., literally trophic). The impression of a vascular disorder is strengthened by 0 the improvement following stellate ganglionectomy. 음 The success of this treatment is mentioned by a $\frac{\bar{s}}{\frac{1}{6}}$ number of authors (McKenzie, 1933; Dott, 1951; $\frac{\AA}{\varnothing}$ Harris, 1940). It seems likely that the true cause of these ulcers is self inflicted trauma (Freeman, 1966). This is not always obvious as the behaviour may be. unconscious, covert and sometimes denied. Neverthe- $\overrightarrow{\vec{\omega}}$ less, the fact that the patients constantly pick at or $\stackrel{\sigma}{\sigma}$ scratch the ulcers is remarked upon by various 8 observers (Howell, 1962; Spillane \& Wells, 1959). Such 3 behaviour may be caused by abnormal sensation in the area. Itching or crawling sensations in the anaesthetic $\vec{v}$ area are common after gasserian ganglion injection $\vec{v}$ but do not seem more pronounced in ulcer cases than in others. The sensation of a blocked nose may be $\overrightarrow{0}$ important (Howell, 1955).

In the present cases the true cause of the ulcers was not in any doubt. Being disinhibited by their primary $z$ disorder the patients made no attempt to conceal their behaviour which was remarked upon by relatives and $\overrightarrow{0}$ attendants alike. One patient had no abnormal sens\& o tion in the affected area, but the other complained of itching. Further proof was provided in one patier when healing was obtained by a package of measures designed to prevent traumatisation of the area.

Thirty one cases with adequate descriptions have been found in the literature and, of these, 22 followed surgery for trigeminal neuralgia. The average age of these patients $(63.7 \mathrm{y})$ is unremarkable given the age incidence of trigeminal neuralgia but women are over-

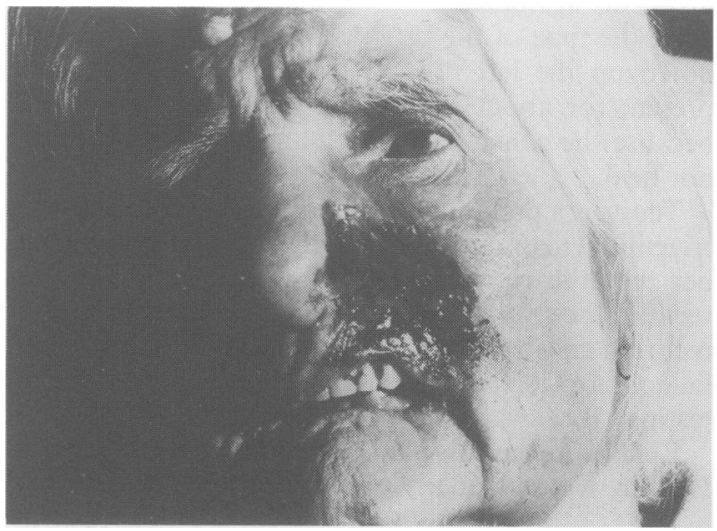

Figure 3 Case 2. Has a characteristic 'sneer' due to scarring and loss of tissue. 
represented (16:6) even allowing for their greater susceptibility to the disease. The remaining 9 had facial anaesthesia due to other causes and were younger, with an average age of $51.3 \mathrm{y}$. Curiously, the female preponderance is even more marked $(7: 2)$. There is no obvious explanation for this.

Mental abnormality is described in 6 patients, an incidence of $19 \%$. Functional problems might be expected in patients suffering from prolonged and intractable pain, but this still leaves 4 where intellectual impairment is specifically mentioned. Frequently a long time-lapse is seen between operation and the onset of the lesion. This is remarkable and does

\section{References}

ADSON (1926). Surgical treatment of trigeminal neuralgia. Annals of Otolaryngology, 35, 601.

DADE LUNSFORD, L. (1982). Treatment of tic douloureux by percutaneous retro-gasserian glycerol injection. Journal of the American Medical Association, 248, 449.

DOTT, N.M. (1951). Facial pain. Proceedings of the Royal Society of Medicine, 44, 1034.

FREEMAN, A.G. (1966). Neurotrophic ulceration of the face with erosion of the ala nasi in vascular disorders of the brain stem. British Journal of Dermatology, 78, 322.

HARRIS, W. (1940). An analysis of 1,433 cases of paroxysmal trigeminal neuralgia (trigeminal-tic) and the end-results of gasserian alcohol injection. Brain, 63, 209.

HENDERSON, W.R. (1967). Trigeminal neuralgia: the pain and its treatment. British Medical Journal, 1, 7.

HOWELL, J.B. (1962). Neurotrophic changes in the trigeminal territory. Archives of Dermatology, 86, 442.

HOWELL, R.G. (1955). Trophic changes in the skin after suggest that facial anaesthesia on its own is not enough to cause an ulcer.

In the present cases it is clear that the added factor was mental impairment of a degree sufficient to prevent the inhibition of self injury. This lesion may well be seen more frequently as more survivors of trigeminal surgery live to ages where dementia is common.

\section{Acknowledgements}

I wish to thank Mrs G. Black for German translations and Mrs Alison Rhodes for the typescript.

operations on the trigeminal nerve. British Journal of Dermatology, 67, 444.

JAEGER, H. (1950). Un type nouveau d'ulcère neurotrophique de l'aile du nez après neurotomie rétrogassérienne. Dermatologica (Basel), 100, 201.

McKENZIE, K.G. (1933). Observations on the results of operative treatment of trigeminal neuralgia. Canadian Medical Association Journal, 29, 492.

MORELLO, G., BIANCHI, M. \& MICLAVACCA, F. (1971). Combined extra-intradural temporal rhyzotomy for the treatment of trigeminal neuralgia. Results in 409 patients. Journal of Neurosurgery, 34, 372.

PEET, M.M. \& SCHNEIDER, R.C. (1952). Trigeminal neuralgia. A review of six hundred and eighty-nine cases with a follow-up study on sixty-five per cent of the group. Journal of Neurosurgery, 9, 367.

SPILLANE, J.D. \& WELLS, C.E.C. (1959). Isolated trigeminal neuropathy. A report of 16 cases. Brain, 82, 391. 